Hammer invited him to the fossil and mineral show in Tucson, Arizona, in about 1995 to see the Thescelosaurus heart, which he was trying to sell. Hammer has said he found the fossil in 1993 in the Hell Creek formation on private land in northwest South Dakota.

Using funds raised by a support group, the North Carolina museum paid Hammer $\$ 350,000$ for the Thescelosaurus. When told that federal records showed that Hammer pleaded guilty in September 1994 to two charges of trafficking in artefacts stolen from federal land in Utah, Russell said he was unaware of this.

In 1990, when federal and state authorities raided Hammer's home, records show they found Native American human remains, which were repatriated to a Californian tribe in 1996. Through his wife, Hammer has denied any impropriety over the Thescelosaurus specimen. She attributes the earlier prosecutions to overly aggressive law enforcement in an area of changing, confusing legislation.

Earlier this month, North Carolina palaeontologists took CT scans of the heart specimen at the university's veterinarian college. Museum officials say they are clearer and more helpful than the original scans. But some palaeontology authorities say no conclusion can be drawn until the remnant is cut open.

| http://www.dinoheart.org

\title{
World Bank is urged to give greater priority to science
}

\section{Colin Macilwain, Washington}

A prominent US economist has criticized Western governments and the World Bank for failing to acknowledge the full potential of science, technology and innovation in alleviating global poverty.

The criticism has come from Harvard University professor Jeffrey Sachs, director of the Center for International Development and former director of the Harvard Institute for International Development. He told the President's Committee of Advisors on Science and Technology (PCAST) last week that the World Bank's policies, based on the premise that open markets and good government would create growth in poor countries, were "vastly inadequate".

"There's a huge missing piece" in conventional thinking about development, Sachs told the PCAST meeting. "That is the recognition that technological change is the main driver of economic growth, but that it doesn't emerge endogenously in tropical countries."

The attack was on the World Development Report 2000/2001 — released by the World Bank on 12 September — which emphasizes "opportunity, empowerment and security" as the keys to poverty alleviation. "There's no recognition in this document of where the

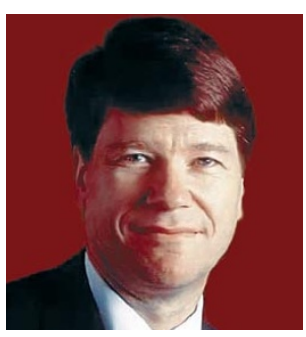

Sachs: critical of policies to tackle global poverty. real problems lie," he claimed.

Sachs proposed three ways to mobilize science and technology in developing countries: the direct transfer of technologies, such as vaccines, from rich countries; the spread of technology through the globalization of manufacturing; and the construction of science and technology development capacity in the developing countries themselves.

World Bank officials responded vigorously to the charges. Nora Lustig, director of the World Development Report at the World Bank, said in an interview that the importance of science and technology was repeatedly acknowledged in the document.

The World Bank is currently developing a new science and technology strategy. And supporters of science at the bank say they are gradually winning support for the idea that science and technology are vital to development, even in the poorest countries.

http://www.worldbank.org/poverty/wdrpoverty

\section{Hunt for Higgs particle wins time for CERN collider}

\section{Alison Abbott}

Physicists at the European Laboratory for Particle Physics (CERN) near Geneva believe that a new analysis of their recent observations indicates an increased probability that they have witnessed the transitory creation of their current Holy Grail - the Higgs boson.

Although they do not rule out the possibility that there may be another explanation for the events they have observed, the analysis helped physicists last week to convince CERN's director-general, Luciano Maiani, to extend the operation of its Large Electron-Positron (LEP) collider by a month.

LEP was to have been switched off at the end of this month to allow construction to start on its successor, the Large Hadron Collider (LHC). Keeping LEP running for an extra month will cost SFr7 million (US\$4 million). This will be found by shuffling CERN's existing budget, although Maiani says it will not disrupt LHC's schedule, or increase its cost.

Scientists working on LEP's four detector

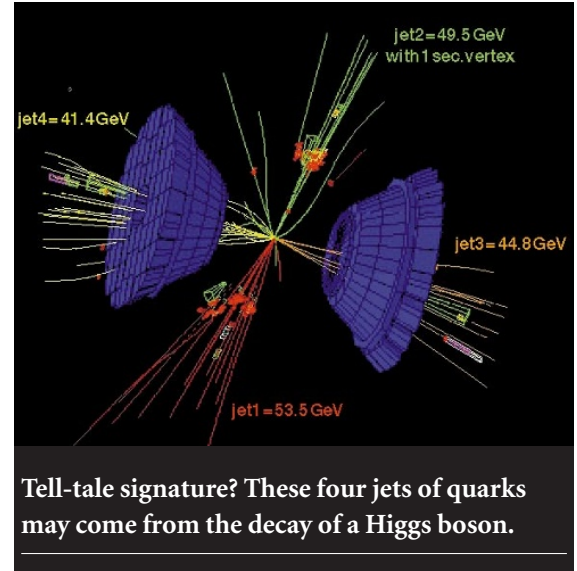

experiments had requested a temporary reprieve because their pooled results had pinpointed five 'events' that could be interpreted as evidence for the existence of the elusive particle. The Higgs boson is thought to be produced when electrons and positrons collide at an energy of around 115 giga-electron volts (see Nature 407, 118; 2000)

Re-analysis of the results shortly before last week's decision had produced a fivefold

๑ 2000 Macmillan Magazines Ltd reduction in the odds - to 1 in 1,000 - that the observed decay patterns, or 'signatures', are random events. But these odds are still four orders of magnitude too high for physicists to say that the existence of Higgs has been demonstrated conclusively.

LEP's temporary reprieve will allow its scientists to double the amount of data they can collect from particle collisions at the high energy levels that LEP was originally designed to achieve. If the signatures of the boson continue to be seen, the confidence limits will have been increased by two orders of magnitude.

"We are excited," says Tiziano Camporesi, head of LEP's DELPHI experiment. But he points out that the observations still have to be confirmed not only with a higher degree of confidence, but also in a way that is consistent across all detector experiments and all decay modes of the particles involved in the collisions. So far, no events have been seen in other decay modes apart from those involving the creation of quarks.

http://cern.web.cern.ch/CERN 